\title{
MOTIVATIONS ANALYSIS IN ECOTOURISM THROUGH AN EMPIRICAL APPLICATION: SEGMENTATION, CHARACTERISTICS AND MOTIVATIONS OF THE CONSUMER
}

\author{
Mauricio CARVACHE-FRANCO* \\ Espíritu Santo University, Km. 2,5 vía Samborondón, Ecuador, \\ Universitat Politècnica de Valencia, Management Department, 7D building, \\ Camino de Vera s/n 46022. Valencia, Spain, e-mail: mauricio2714@hotmail.com \\ Marival SEGARRA-OÑA \\ Universitat Politècnica de Valencia, Management Department, 7D building, \\ Camino de Vera s/n 46022. Valencia, Spain, e-mail: maseo@omp.upv.es

\section{Conrado CARRASCOSA-LÓPEZ} \\ Universitat Politècnica de Valencia, Management Department, 7D building, \\ Camino de Vera s/n 46022. Valencia, Spain, e-mail: concarlo@upvnet.upv.es
}

\begin{abstract}
Citation: Carvache-Franco, M., Segarra-Oña, M., \& Carrascosa-López, C. (2019). MOTIVATIONS ANALYSIS IN ECOTOURISM THROUGH AN EMPIRICAL APPLICATION: SEGMENTATION, CHARACTERISTICS AND MOTIVATIONS OF THE CONSUMER. GeoJournal of Tourism and Geosites, 24(1), 60-73. https://doi.org/10.30892/gtg.24106-343
\end{abstract}

\begin{abstract}
In recent years, there has been a growing interest of tourists in the environment and movements directed towards the enjoyment of the natural environment. This study is designed to analyze the motivations and the demand segmentation in ecotourism taking as reference the functional theory. The empirical analysis was carried out in Santay Island National Recreation and Morro Mangrove Refuge in Ecuador. About the data analysis, a factorial analysis and a k-means non-hierarchical segmentation were performed. The results show that there are several motivational factors in ecotourism: "Self-development", "Interpersonal relationships", "Building personal relationships and Ego-defensive function", "Reward", "Escape", "Nature appreciation". There are three segments of ecotourists: "Multiple motives", "Nature", and "Reward and Escape".
\end{abstract}

Key words: Motivations, Segmentation, Tourism, Ecotourism, Ecuador

$$
* \quad * \quad * \quad * \quad *
$$

\section{INTRODUCTION}

Ecotourism has 5\% annual growth rate worldwide and grows three times faster than tourism in general (Hultman et al., 2015). So there is a growing interest of tourists in environment and movements directed towards the enjoyment of the natural environment

\footnotetext{
* Corresponding author
} 
Motivations Analysis in Ecotourism Through an Empirical Application:

Segmentation, Characteristics and Motivations of the Consumer

(Rivera, 2010). Ecotouristic areas have become important destinations, due to their efficiency in protecting the environment, education, recreation and job creation (Tao \& Wall, 2009). In addition, ecotourism is a strategy to improve: conservation and local communities in protected areas (Jalani, 2012). However, Community-based tourism projects will only succeed if successful integrated marketing is undertaken to ensure that the marketing outlays are successful in cultivating sustainable tourism demand (Strydom et al., 2019). In addition, Local authorities must be convinced tourism is a viable and valuable activity that can economically revitalise the area and generate additional income for the local population (Vijulie et al., 2018). On the other hand, studies indicate that the most effective predictor of tourism behavior should be the behavior itself, including the motivations (Goeldner \& Ritchie, 2003; Johns \& Gyimothy, 2002; Kotler et al., 2003). In this sense, the study of the motivations allows a better understanding of expectations, needs and objectives of tourists and is a fundamental element to design marketing strategies, also to help the positioning and competitiveness of involved agents in the tourist activity (Pons et al., 2007). On the other hand, tourists have different reasons to visit different attractions and destinations related to nature (Chikuta et al., 2017). In this way, is essential for tourism managers to recognize that ecotourist's motives are different (Álvarez, 2012).

Market segmentation has been widely used to identify the niche markets of different touristic products and services (Park \& Yoon, 2009) and it is developed from behavior theories such as motivation or recreational specialization (Kim et al., 2008). In this sense and according to several authors, the segmentation of travelers based on motivations is one of the most effective methods (Crompton, 1979; Schewe, 1990). Therefore, to manage effectively a tourist destination it is necessary to know the main reasons that attract visitors and identify consumer segments, developing commercial strategies adapted to the target groups (Meiriño et al., 2016). In addition, tourism products designed according to the needs of consumers could be easily identified; the formulation, promotion and delivery of these products is facilitated (Park \& Yoon, 2009).

However, the lack of information about the different ecotourism segments hinders efficiency in promotion programs specifically targeted (Park \& Yoon, 2009). Also, it is important to consider that the providers of tourist services in a destination must understand needs and desires of tourists to manage the destination resources and attract different groups of tourists (Pesonen, 2012). In other words, more information about the market and the segments that comprise it, it is easier to design products or services that can satisfy customers (Pulido-Fernández \& Sánchez-Rivero, 2010). However, demand segmentation studies in the different ecotourism segments are scarce (Weaver \& Lawton, 2002). To address this gap in research, this study aims to present an analysis of the demand segmentation and motivations in ecotourism, to provide information that will help to plan marketing strategies for each segment to tourism marketers. It is a contribution to the debate about demand in ecotourism. To fulfill this objective, the article is structured, after the introduction, the second section where the literature is reviewed, the third section describing the study area, the fourth section that presents the research methodology, the fifth section with the results of the investigation and the sixth section with the discussion and conclusions of the study.

\section{THEORETICAL FRAMEWORK}

\section{Motivations in ecotourism}

Swanson and Horridge (2006) defined motivation as a set of needs that make a person involved in touristic activities. They are psychological needs and desires that provoke, direct and integrate behavior and activity (Pearce, 2013). Therefore, it is the 
central factor in the decision-making process (Yolal et al., 2015). Motivational factors are defined as psychological needs that play an important role in making a person feel a psychological imbalance that can be corrected through a travel experience (Crompton, 1979; Kim et al., 2000). On the other hand, Álvarez (2012) points out that ecotourism supposes to identify nature as the main motivation to travel, to acquire more knowledge about this natural environment and to become aware of its role.

In contrast, Del Valle (2007) considers the main motivations of rural tourism (ecotourism, agrotourism and adventure tourism): An environment with rural characteristics (low population density, slightly crowded) and naturalness. Attractive physical environment (good climate, presence of mountains, forests, waterbodies, etc.). The possibility to practice sports or outdoor activities is an additional attraction for some of the modalities of rural tourism. Architecture with traditional characteristics, adapted to the environment conditions and with aesthetic values. Maintenance of cultural values such as holidays, traditions, ways of life or local gastronomy.

One of the studies about motivation in ecotourism from Panin and Mbrica (2014) who through a descriptive investigation found the most important motivations for ecotourists in the Republic of Serbia. They divide the motivations into 4 groups: sports and health, motivation for nature, cultural and educational activities, and social activities. The motivations related to sports and recreational activities, the positive impact on health, walking in the forest, seeing and enjoying nature, are the main motivations in ecotourism. Another study about motivations in ecotourism is from Lee et al. (2014) who through a factorial analysis analyzed the tourists of ecological parks restored in South Korea, concluding that there are seven factors related to the motivations: Self-development, Interpersonal relationships, Reward, Building personal relationships, Escape, Ego-defensive function, Nature appreciation.

Regarding the ecotourists' characteristic, Álvarez (2012) points out that they are restless and active people who need to try the leisure possibilities that are compatible with the environment, activities in which nature prevails over the interests of human beings. Also to enjoy personal life development that allows the physical activities, the experience to become familiar with new lifestyles, meeting people with similar concerns, attending cultural events and buying local handicrafts. They also show a preference for small groups and personalized service. On the other hand, Cheng et al., (2016) consider that ecotourists would positively influence on the intention, interest and willingness to pay a higher price for ecotourism products and services. In this sense, Nickerson et al. (2016) concluded that sustainable tourists are willing to spend more, which can increase the benefit of offering sustainable tourism destinations. On the other hand, Ma et al. (2018) conducted a study in the Nanling National Forest Park and the Dinghushan National Nature Reserve, finding that the most important factor in Chinese tourists is "relaxation and nature exploration". In contrast, Chow et al. (2019) conducted a study to visitors to the Ramsar wetland in Hong Kong, finding that the most important motivations were relaxation, escape from daily life, and physical and mental health.

The theory used in this study is the functional theory, introduced by Katz (1960), who proposed that there are four motivational functions: knowledge function, expressive value function, self-defense function and utilitarian function.

From the sociology literature, Smith et al. (1956) added another function, a function of social adjustment. The knowledge function focuses on the desire to obtain information to understand the world. Knowledge variables such as learning, meeting 
Motivations Analysis in Ecotourism Through an Empirical Application:

Segmentation, Characteristics and Motivations of the Consumer

new people, appreciating nature and being with like-minded people correspond to the knowledge function. While the desire for knowledge is not an absolute desire to understand the entire universe, people want to understand the events that affect their own lives (Houle et al., 2005). The ego defense function emphasizes the reduction of social pressure by participating in an event. An individual finds means that will allow him to avoid or escape an unpleasant internal or external reality. As a result, the individual can choose to be adaptable to the contemporary event by eliminating anxiety. The elimination of anxiety can be achieved through commitment, such as being a member of a society and joining discussions about topics of similar interest with substantive rationality (Lee et al., 2014). The utilitarian function emphasizes the minimization of punishment and the maximization of rewards (Fodness, 1994). Measurement of utilitarian function can include gaining self-confidence, being independent, having fun, experiencing different cultures, and avoiding stress. Finally, the social adjustment function describes an acceptable norm for other associates, including family members, relatives and friends (Lee et al., 2014).

\section{Demand segmentation in ecotourism}

According to Ho et al., (2012) market segmentation represents the decisive criterion to determine which groups of clients we should contact. The segmentation of heterogeneous tourists according to their motivations allows tourism providers to create products and services preferred and valued by the destination markets (Lee et al., 2004). In this sense, the market segmentation strategy can be used to identify specific groups of tourists, provide better tourism packages, increase the benefits for destinations and develop a more efficient tourism policy and marketing planning (DíazPérez et al., 2005; Nickerson et al., 2016; Xia et al., 2010).

One of the segmentation studies of the demand for motivations in protected natural areas from Cordente-Rodríguez et al., (2014) who through a segmentation by latent classes analyzed the visitors in the protected area of "Serranía Alta" Cuenca (Spain). Two groups were found: Nature: has a unique motivation to enjoy nature and resources. Multiple motive: has a combination of several reasons such as enjoying nature and gastronomy, and visiting villages to learn about cultures and traditions.

Another study about demand segmentation in ecotourism from Barić et al., (2016) who through a factorial and a cluster K-means analysis conducted a study of visitors to Paklenica National Park in Croatia, they find 3 groups: Naturalist: the enjoyment of nature is the most important. Escapists: have a desire to escape and leave the solitude, with moderate interest in nature. Ecotourists: enjoy nature and novelty with educational interest and learn from experiences. In contrast, Neuts et al., (2016) analyzed market segments that cause economic impacts on ecotourism in Shiretoko, Hokkaido, Japan. The study found four segments: Bear-watchers: motivated mainly by bears observation, and they go on excursions to waterfalls or visit the Nature Center of Shiretoko National Park as secondary activities. Landscape-lovers: the elements of the landscape are the main reason for a visit. Organized tour groups: their motivations are the elements of the landscape and whale observation. Active explorers: are tourists with wide motivations. They prefer the elements of the landscape, but also the fauna as bear and bird observation.

Another study, that of Gu et al. (2018), was conducted in the Changbai Mountain Biosphere Reserve in northeastern China, finding four groups: "nature travelers", interested in experiencing nature and appreciating natural landscapes; "cultural landscape tourists", interested in participating in and appreciating nature and natural landscapes; "food and shopping enthusiasts", showing a medium-high interest for the natural and cultural features of the reserve; and "eclectic adventurers", expressing a wide range of motivations to 
visit the reserve, with higher average scores on most motivational factors. Likewise, Jeong et al. (2018) conducted a study in Kuang Si Waterfall and Konglor Cave in Lao People's Democratic Republic, finding four segments: "nature and cohesion-seeking tourists", "nature-seeking tourists", "passive nature-seeking tourists", and "want-it-all tourists". In contrast, Carvache et al. (2019) conducted a study in protected Areas in Guayas, find three segments: Firstly, there is a multiple motives group, with high motivation in all the motivational variables. Secondly, there is a nature group, with high motivation in aspects related to nature. Thirdly, there is a reward and escape group, with high motivation related to nature, fun, exploring the unknown, and escaping from routine.

\section{EMPIRICAL APPLICATION}

Ecuador is a mega diverse country which has 51 protected areas (Ministry of Environment, 2018), they are visited by national and international tourists. The province of Guayas, located in the coast of Ecuador, has important protected areas. For the present study, the Santay National Recreation Area and Morro Mangrove Wildlife Refuge were selected. These two places were chosen for their natural and cultural characteristics related to ecotourism. In other words, they are very visited because of the proximity to Guayaquil city, also they have attractions and ecotourism activities.

\section{Santay National Recreation Area}

Santay Island is located between the cities of Guayaquil and Duran, in the middle of the great Guayas River, in the Province of Guayas. This place has a wide variety of bird species, confirming its status as a natural refuge, leading it to be internationally recognized as the number 1041 (RAMSAR) place in the world since 2000.

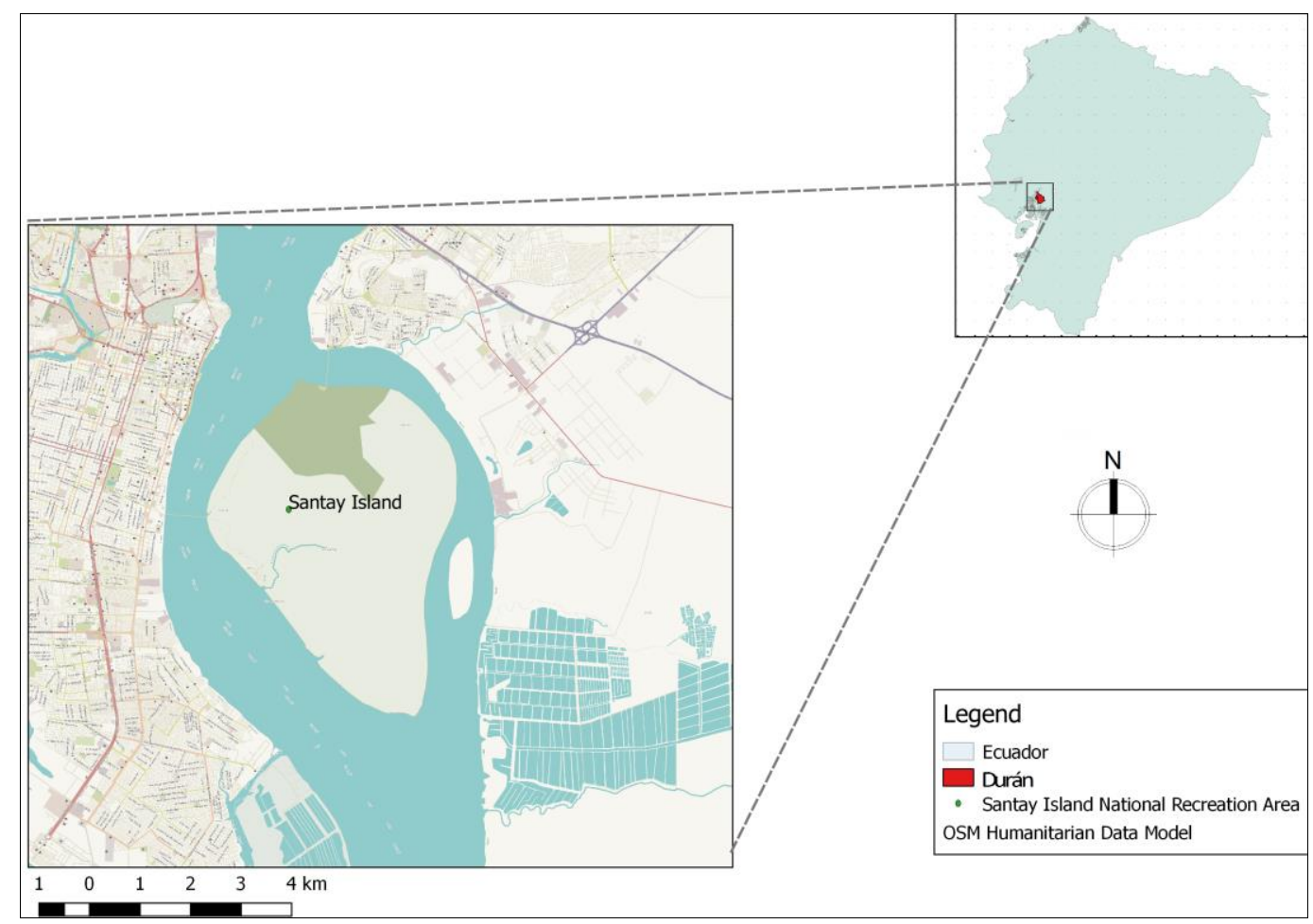

Figure 1. Geographical Location of Santay National Recreation Area (Ecuador) 
Motivations Analysis in Ecotourism Through an Empirical Application:

Segmentation, Characteristics and Motivations of the Consumer

Its declaration as a Ramsar place makes this place very important, with global interest and priority for conservation. In 2010, Santay Island was declared as a National Recreation Area by the Environment Ministry due to its environmental importance and for recreational purposes. This site is a wetland visited by waterfowl to rest, for a shelter and nesting. This wetland protects 60 plant species, 12 reptile varieties and 128 types of birds, 12 vulnerable and threatened birds are on the International Trade in Endangered Species List and the World Conservation Union. In addition, this place is important for its mangroves. In addition to its vegetation, several trees are already very scarce and offer protection to some mammals that are already rare. Among the main attractions in flora and fauna, there are mangroves and seabirds that tourists observe while they sail through the estuaries. Another attraction is the Ecovillage because tourists can visit it and appreciate some crocodiles (Figure 1).

\section{Morro Mangroves Wildlife Refuge}

It is located on "Malecon" street, Morro Port (Rural area) in Guayas Province. The refuge is located to the north of Guayaquil Gulf, where Morro channel or stream begins. The main reason for its declaration as a protected area is the existence of a large population of dolphins that inhabit Morro channel and the frigate colony in "Manglecito Island". In this place, there are four types of mangroves: red, white, jelí or button and black. In addition, the refuge mainland protects a small dry forest patch. Among the fauna, visitors find more than 80 species in this place, seabirds are the most abundant in the refuge. The main attractions are the observation of dolphins, frigate birds, pelicans and blue-footed boobies, roseate spoonbill, white ibis and cormorants.

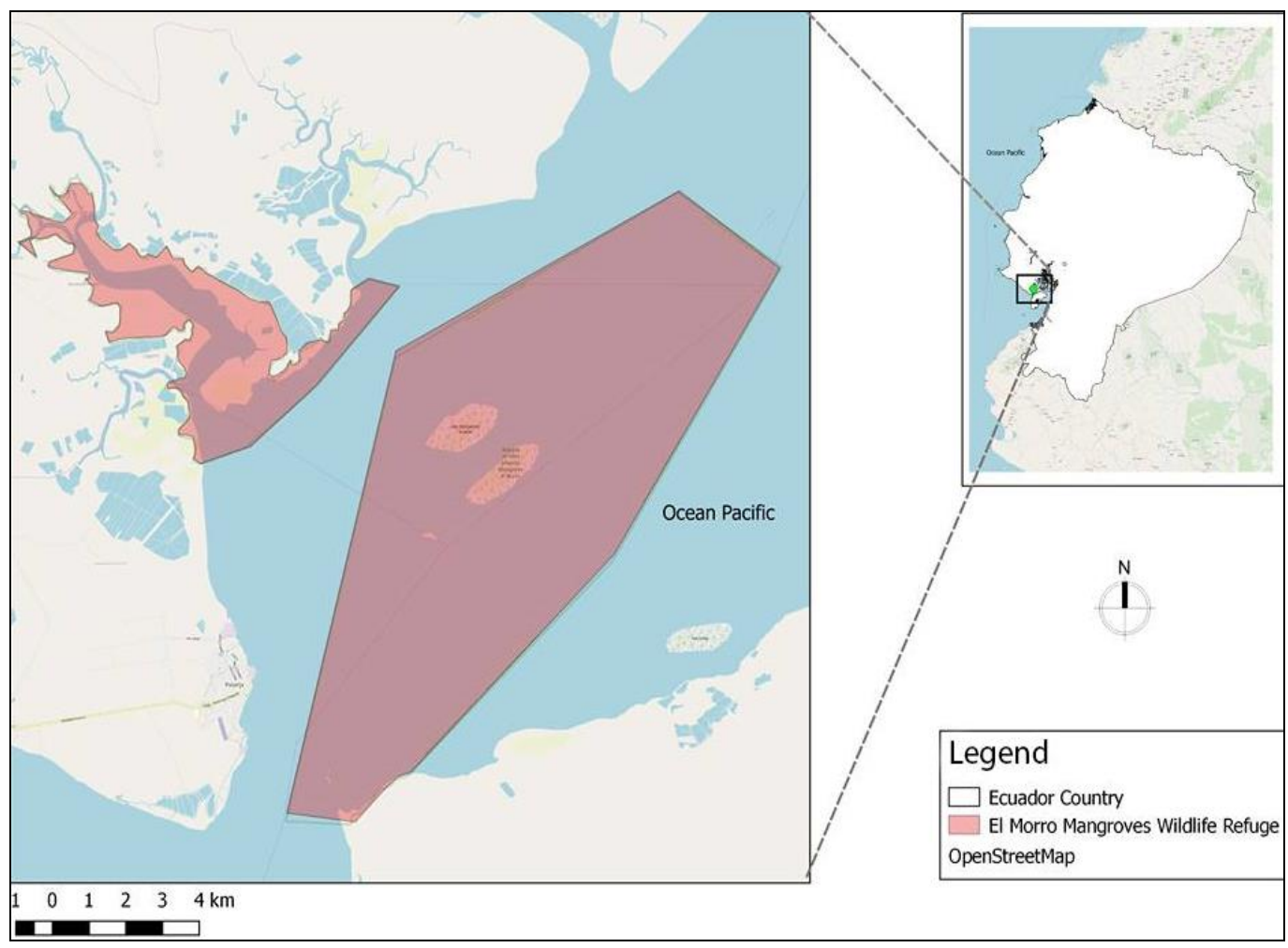

Figure 2. Geographic Location of Morro Mangroves Wildlife Refuge (Ecuador) 
On Manglecito Island, there are roosts and nesting places for frigates, pelicans and blue-footed boobies. It is estimated that the colony of frigates is about 6,000 individuals, which makes it one of the highest concentration place of these birds in Ecuador. In another place called "Farallones", the colonies of blue-footed boobies and pelicans stand out at the entrance of the estuary (Figure 2).

\section{METHODOLOGY}

The present empirical research was based on a fieldwork, a questionnaire was applied based on different previous studies about motivations and segmentation of demand in ecotourism (Crompton, 1979; Fodness, 1994; Weaver \& Lawton, 2002: Galley \& Clifton, 2004; McGehee \& Kim, 2004; Jang \& Wu, 2006; Lee et al., 2014). The sample collection was carried out from January to March 2018. The survey aimed national and international tourists over 18 years old who were visiting the two protected areas in the Ecuadorian coast: Santay National Recreation Area and Morro Mangrove Wildlife Refuge. The distribution of the surveys was carried out according to the method of simple random sampling in the aforementioned protected areas. The questionnaires were filled in place while the visitors were doing some recreational activity in both protected areas.

The tourists filled out surveys independently, and interviewers were ready to solve any question. The interviewers were students from tourism career in ESPOL University (Guayaquil), who were trained to obtain the sample in the study areas. The questionnaire consisted of Likert questions of 5 points, where 1 was little and 5 a lot. 162 valid surveys were obtained, with a margin of error of $+/-7.8 \%$ and a confidence level of $95 \%$.

The Combrach's alpha coefficient reached the value of 0.97 , which indicates a meritorious index on the scale. The data was analyzed in two stages: First, a factor analysis was carried out that helped to identify the constructs that underlie the variables, providing a global view of the most substantive motivations using such constructs. Factor analysis has been widely used in visitor segmentation research (Formica \& Uysal, 1998; Kastenholz et al., 1999; Johns \& Gyimothy, 2002). Specifically, Varimax rotation was used to facilitate the interpretation of the data.

The Kaiser criterion was used to find the number of factors, where only the factors with eigenvalues greater than 1 were used. The KMO index (Kaiser-MeyerOlkin) and the Bartlett sphericity test were used to know if it was appropriate to perform the factorial analysis. The Combrach's alpha coefficient was used to measure the reliability of the measurement scale. In the second stage, the K-means grouping method was implemented, which is commonly used in tourism segmentation research (for example, Formica \& Uysal, 1998, Kau \& Lee, 1999). The differences between the groups in relation to the motivations were evaluated by means of adequate analyzes including ANOVA, and the Brown-Forsythe and Welch statistics. For the post hoc analysis, the Games-Howell test was used. Finally, the Chi-Square analysis was used to explore the differences between the groups in terms of sociodemographic variables, satisfaction and intentions to return to the destination. The data collected was organized, tabulated and analyzed using the SPSS 22.0 program for Windows.

\section{RESULTS}

\section{Motivations in ecotourism}

A factorial analysis has been carried out which allowed to extract six motivational dimensions. The analysis of the main component has been used as a technique used for data reduction. The varimax rotation method was used to obtain a clearer interpretation of the factors, so that each one had very high or low loadings on the factors. For the 
Motivations Analysis in Ecotourism Through an Empirical Application:

Segmentation, Characteristics and Motivations of the Consumer

number of factors that were used in the Kaiser criterion where factors that have eigenvalues greater than $\mathbf{1 . 0 0}$ are taken into account. Six factors are part of the solution and represent $74.8 \%$ of the total variance, this is a sufficient total variance value because increasing a factor with an eigenvalue less than 1 will not provide enough information to the model, thus it will increase a bit more the total variance. The KMO index (KaiserMeyer-Olkin) is close to one, so the relationship between the variables is high and a factor analysis is appropriate. In addition, Barlett's sphericity test is significant <0.05, so the factorial analysis must be applied. The results are shown in Table 1.

Table 1. Factorial analysis of motivational variables

\begin{tabular}{|c|c|c|c|c|c|c|c|}
\hline \multirow{2}{*}{ Items } & \multicolumn{6}{|c|}{ Loanding } & \multirow{2}{*}{ Factors } \\
\hline & $\mathbf{1}$ & 2 & 3 & 4 & 5 & 6 & \\
\hline To gain a new perspective on life & 0.794 & & & & & & \multirow{7}{*}{$\begin{array}{c}\text { Factor 1: } \\
\text { Self- } \\
\text { development }\end{array}$} \\
\hline To know what I am capable of & 0.755 & & & & & & \\
\hline Para tener un sentido de confianza de mí mismo & 0.727 & & & & & & \\
\hline To be independent & 0.693 & & & & & & \\
\hline To understand more about myself & 0.683 & & & & & & \\
\hline To feel inner harmony/peace & 0.634 & & & & & & \\
\hline To have the opportunity to know me better & 0.605 & & & & & & \\
\hline To strengthen relationship with my family & & 0.843 & & & & & \multirow{6}{*}{$\begin{array}{l}\text { Factor 2: } \\
\text { Interpersona } \\
\text { relationships }\end{array}$} \\
\hline To contact family and friends who live elsewhere & & 0.822 & & & & & \\
\hline To reflect on past memories & & 0.708 & & & & & \\
\hline To feel that I belong & & 0.703 & & & & & \\
\hline To reminisce about parents' time & & 0.686 & & & & & \\
\hline To think about good times I have had in the past & & 0.563 & & & & & \\
\hline To know the locals & & & 0.762 & & & & \multirow{8}{*}{$\begin{array}{l}\text { Factor 3: } \\
\text { Building } \\
\text { personal } \\
\text { relationships } \\
\text { and Ego- } \\
\text { defensive } \\
\text { function }\end{array}$} \\
\hline To meet people with similar interests & & & 0.664 & & & & \\
\hline To join the social discussion & & & 0.662 & & & & \\
\hline To follow current events & & & 0.661 & & & & \\
\hline To join interest of people & & & 0.614 & & & & \\
\hline To meet new people & & & 0.593 & & & & \\
\hline To be with others if I need them & & & 0.516 & & & & \\
\hline To visit destination & & & 0.409 & & & & \\
\hline To develop my personal interests & & & & 0.715 & & & \multirow{6}{*}{$\begin{array}{l}\text { Factor 4: } \\
\text { Reward }\end{array}$} \\
\hline To experience new things & & & & 0.681 & & & \\
\hline To explore the unknown & & & & 0.681 & & & \\
\hline To have fond memories & & & & 0.676 & & & \\
\hline To have a sense of self-achievement & & & & 0.597 & & & \\
\hline To experience different cultures & & & & 0.538 & & & \\
\hline To avoid daily stress & & & & & 0.853 & & \multirow{4}{*}{$\begin{array}{l}\text { Factor 5: } \\
\text { Escape }\end{array}$} \\
\hline To be away from the crowds of people & & & & & 0.749 & & \\
\hline To escape from routine & & & & & 0.712 & & \\
\hline To avoid interpersonal stress & & & & & 0.686 & & \\
\hline To be close to nature & & & & & & 0.861 & \multirow{2}{*}{\begin{tabular}{|c|} 
Factor 6: \\
Nature \\
appreciation
\end{tabular}} \\
\hline To get a better appreciation of nature & & & & & & 0.816 & \\
\hline Auto values & 16.435 & 3.12 & 1.889 & 1.747 & 1.229 & 1.01 & \\
\hline \% variance explained & 48.3 & 9.2 & 5.6 & 5.1 & 3.6 & 3.0 & \\
\hline \% cumulative variance & 48.3 & 57.5 & 63.1 & 68.2 & 71.8 & 74.8 & \\
\hline KMO & \multicolumn{6}{|c|}{0.919} & \\
\hline Bartlett's sphericity test & \multicolumn{6}{|c|}{ Chi squared $=5161.946 \mathrm{sig}=0.000$} & \\
\hline
\end{tabular}


This third dimension is related to a motivated visitor by meeting new people, people with similar interests, to join the interests of people, follow current events, meet new people and know about the destination. In addition, it is related to the defensive function of the ego and the function of knowledge according to functional theory. The fourth factor was called "Reward", and comprised $1.74 \%$ of the total variance. This fourth dimension refers to a visitor motivated by having fun, experiencing new things, exploring the unknown, obtaining good memories and experiencing different cultures. Likewise, it is linked to the utilitarian function according to the functional theory. The fifth factor was called "Escape", and comprised $\mathbf{1 . 2 2 \%}$ of the total variance. This fifth dimension is associated to a visitor motivated by escaping routine and being away from daily stress or crowds. The utilitarian function according to the functional theory. The sixth factor was called "Nature appreciation", and comprised $1.01 \%$ of the total variance. This sixth dimension is associated to visitors motivated by nature. It is also related to the function of knowledge according to functional theory. The results are similar to Lee et al. (2014) who conclude that the functional theory in the context of ecotourism is valid, which indicates that the intentions of ecotourists to revisit the restored ecological parks are influenced by a variety of motivating functions. They obtained 7 motivational factors in their study: Self-development, Interpersonal relationships, Reward, Building personal relationships, Escape, Ego-defensive function, Nature appreciation.

\section{Demand segmentation in ecotourism}

For this part of the investigation, an analysis of non-hierarchical K-means clusters has been carried out. Under the criterion of maximizing the variance between typologies and minimizing the variance within each typology, the best solution that meets the criteria is that which establishes three conglomerates. The characterization of the clusters from the averages of the motivation variables appears in Table 2. The F statistic of the ANOVA allows to contrast that the compared averages are not equal, but it does not allow to specify where the detected differences are. To know which mean differs from another, the contrast called multiple post hoc comparisons has been used. In order to make these comparisons it can not be assumed that the population variances are equal.

The F statistic of the ANOVA is based on the fulfillment of the assumptions of normality and homoscedasticity. Indeed, it is not possible to assume that the population variances are equal, because the critical level associated with the Levene statistic is less than 0.05, the Brown-Forsythe and Welch statistics are used as an alternative to the ANOVA F statistic. Since the critical level associated with both statistics is less than 0.05, we can reject the hypothesis of equality of means and conclude that the averages of the motivational variables of the three comparative groups are not equal. To contrast the significant differences between the different means, the Games-Howell test has been applied. As Table 2 shows, in the first group there are visitors who have high motivation in all the motivational variables, which is why this group has been called "Multiple Motives". In addition, they are related to all motivational dimensions. Visitors who have a high motivation in aspects related to nature and experience new things form the second group, that is the reason why these visitors have been called "Nature". In addition, they are related to the dimension nature appreciation.

The third group are visitors who have high motivations related to nature, fun, obtaining memories, experience with new things and experience with different cultures, which is why this group has been called "Reward and Escape". Likewise, they are related to the dimensions of appreciation of nature, reward and escape. The results are similar as Cordente-Rodríguez et al. (2014), who found two groups: Nature and Multiple motive, finding in this study the "Reward and Escape" as the third group. 
Motivations Analysis in Ecotourism Through an Empirical Application:

Segmentation, Characteristics and Motivations of the Consumer

Table 2. Characterization of the clusters based on the motivational variables

\begin{tabular}{|c|c|c|c|}
\hline \multirow{2}{*}{ Variables } & \multicolumn{3}{|c|}{ Cluster } \\
\hline & $\mathbf{1}$ & 2 & 3 \\
\hline To be close to nature & $4.9^{*}$ & 4.3 & 4.3 \\
\hline To get a better appreciation of nature & $4.9^{*}$ & 4.2 & 4.4 \\
\hline To experience new things & $4.9^{*}$ & 4.2 & 4.2 \\
\hline To explore the unknown & $4.9^{*}$ & 3.9 & 4.1 \\
\hline To develop my personal interests & $4 \cdot 7^{*}$ & 3.8 & 3.9 \\
\hline To have fond memories & $4.9^{*}$ & 3.9 & 4.2 \\
\hline To have fun & $4.9^{*}$ & 3.9 & 4.3 \\
\hline To have a sense of self-achievement & $4.8^{*}$ & $2.6^{*}$ & $3 \cdot 7^{*}$ \\
\hline To experience different cultures & $4.9^{*}$ & $3.9^{*}$ & $4.2^{*}$ \\
\hline To meet new people & $4.7^{*}$ & 3.2 & 3.9 \\
\hline To meet people with similar interests & $4 \cdot 7^{*}$ & $2.5^{*}$ & $3 \cdot 7^{*}$ \\
\hline To meet locals & $4.7^{*}$ & $3.0^{*}$ & $3.8^{*}$ \\
\hline To be with others if I need them & $4.5^{*}$ & $2.2^{*}$ & $3.2^{*}$ \\
\hline To have the opportunity to know me better & $4 \cdot 7^{*}$ & 2.1* & $3.6^{*}$ \\
\hline To understand more about myself & $4 \cdot 7^{*}$ & 2.1* & $3.6^{*}$ \\
\hline To gain a new perspective on life & $4.7^{*}$ & $2.5^{*}$ & $3.6^{*}$ \\
\hline To think about the good times I have had in the past & $4.7^{*}$ & $2.2^{*}$ & $3 \cdot 3^{*}$ \\
\hline To know what I am capable of & $4.8^{*}$ & $2.0^{*}$ & $3.4^{*}$ \\
\hline To have a sense of self-confidence & $4.7^{*}$ & $1.9^{*}$ & $3 \cdot 4^{*}$ \\
\hline To feel inner harmony/peace & $4.9^{*}$ & $2.8^{*}$ & $3.9^{*}$ \\
\hline To be independent & $4 \cdot 7^{*}$ & $1.9^{*}$ & 3.4 \\
\hline To reminisce about parents' time & $4.6^{*}$ & $1.5^{*}$ & $3.2^{*}$ \\
\hline To contact family and friends who live elsewhere & $4.6^{*}$ & $1.7^{*}$ & $3.2^{*}$ \\
\hline To feel that I belong & $4.6^{*}$ & $1.7^{*}$ & $3.0^{*}$ \\
\hline To strengthen the relationship with my family & $4.7^{*}$ & 2.0* & $3 \cdot 3^{*}$ \\
\hline To reflect on past memories & $4.6^{*}$ & $1.7^{*}$ & $3.1^{*}$ \\
\hline To visit the destination & 4.8* & 3.0* & $4.1^{*}$ \\
\hline To avoid interpersonal stress & $4.8^{*}$ & 3.0* & $3.9^{*}$ \\
\hline To be away from the crowds of people & $4.9^{*}$ & 3.0* & $3.9^{*}$ \\
\hline To be away from daily stress & $4.9^{*}$ & $3 \cdot 3^{*}$ & $4.1^{*}$ \\
\hline To escape from routine & $4.9^{*}$ & $3.6^{*}$ & $4.1^{*}$ \\
\hline To join the interest of people & $4.7^{*}$ & 2.0* & $\mathbf{3 . 6}^{*}$ \\
\hline To join the social discussion & $4.6^{*}$ & 1.9* & $3.4^{*}$ \\
\hline To follow current events & $4.7^{*}$ & 2.0* & $3 \cdot 3^{*}$ \\
\hline
\end{tabular}

* Bold values show significant differences in at least two of the means of the three conglomerates

\section{Satisfaction and intention to return to the destination in the three segments}

For the relationship of the three segments with the satisfaction and intentions to return, a Chi-Square significance contrast has been made, and in this way we can find the variables that are really relevant for the analysis. A Likert scale of 5 points was used, being 1 little and 5 a lot. The results are shown in Table 3. As shown in Table 3, the segment "Multiple Motives" is characterized because it has a high percentage of very satisfied members (57.1\%), so it is the segment with the highest level of satisfaction in relation to the others. Moreover, they have a high level of intentions to return to the destination (65.1\%), so it is the segment with the highest level of intention to return to the destination in relation to the others. The segment "Nature" is the least satisfied and the group that has less intention to return to the destination in relation to the other segments. On the other hand, 
the segment "Reward and Escape" is characterized because a considerable percentage of its members have a high level of intentions to return to the destination (41.1\%).

Table 3. Relationship of the segments with satisfaction and intentions to return

\begin{tabular}{|c|c|c|c|c|c|}
\hline \multirow{2}{*}{\multicolumn{2}{|c|}{ Variables }} & \multicolumn{3}{|c|}{ Cluster } & \multirow{2}{*}{ Total } \\
\hline & & $\mathbf{1}$ & 2 & 3 & \\
\hline \multirow{5}{*}{ Overall satisfaction } & 1 & & $2.4 \%$ & $1.8 \%$ & $1.3 \%$ \\
\hline & 2 & $1.6 \%$ & & $1.8 \%$ & $1.3 \%$ \\
\hline & 3 & $1.6 \%$ & $34.1 \%$ & $12.5 \%$ & $13.8 \%$ \\
\hline & 4 & $39.7 \%$ & $39.0 \%$ & $60.7 \%$ & $46.9 \%$ \\
\hline & 5 & $57.1 \%$ & $24.4 \%$ & $23.2 \%$ & $36.9 \%$ \\
\hline \multicolumn{2}{|l|}{ Total } & $100.0 \%$ & $100.0 \%$ & $100.0 \%$ & $100.0 \%$ \\
\hline \multirow{5}{*}{$\begin{array}{l}\text { Intentions to return to } \\
\text { the destination }\end{array}$} & 1 & & $2.4 \%$ & & $0.6 \%$ \\
\hline & 2 & $1.6 \%$ & $12.2 \%$ & & $3.8 \%$ \\
\hline & 3 & $3.2 \%$ & $22.0 \%$ & $17.9 \%$ & $13.1 \%$ \\
\hline & 4 & $30.2 \%$ & $41.5 \%$ & $41.1 \%$ & $36.9 \%$ \\
\hline & 5 & $65.1 \%$ & $22.0 \%$ & $41.1 \%$ & $45.6 \%$ \\
\hline \multicolumn{2}{|l|}{ Total } & $100.0 \%$ & $100.0 \%$ & $100.0 \%$ & $100.0 \%$ \\
\hline
\end{tabular}

\section{DISCUSSION AND CONCLUSIONS}

The segmentation based on the motivations of ecotourists is a useful tool for public institutions and private companies to adapt their offer with different groups of ecotourists. Therefore, they improve tourism products and increase the benefit for destinations, so there are more satisfied ecotourists and with high intentions to return to the destination. The main motivational dimension in ecotourism is the "Selfdevelopment", the same that is related to gain self-confidence and be independent. People consider that traveling is an opportunity to enrich their lives. Compared to more commercial forms of travel, ecotourism provides more independent time for people to think about personal matters (Kimmel, 1999). The second dimension in ecotourism is "Interpersonal relationships", related to visitors motivated to contact and strengthen relationships with family and friends. The third dimension in ecotourism is "Building personal relationships and Ego-defensive function", related to a visitor motivated to meet new people or with similar interests, to join the interests of people and follow current events. People tend to behave according to socially desired problems (McGehee \& Kim, 2004). The fourth dimension in ecotourism is "Reward", related to a visitor motivated to have fun, experiencing new things and different cultures, so it is not enough for tourists to be surrounded by nature, but activities must be provided to them, this will generate fun and experience new things.

The fifth dimension in ecotourism is "Escape", related to visitors motivated to escape from routine and to be away from daily stress or crowds. Consequently, people travel to reward themselves and take a break from their routines (Broad \& Jenkins, 2008). The sixth dimension in ecotourism is "Nature appreciation", related to a visitor motivated to appreciate nature. In addition, it is related to the function of knowledge according to functional theory. It is common to say that the appreciation of the natural environment is the predominant motivation of ecotourists (Weaver \& Lawton, 2002; Wurzinger \& Johansson, 2006). The dimensions mentioned in this study are similar to Lee et al. (2014), who mentioned that in ecotourism there are seven motivational dimensions related to functional theory. In addition, the findings of this study support other previous ecotourism research related to tourists' motivations (Weaver \& Lawton, 2002; McGehee \& Kim, 2004; Lee et al., 2014). Regarding the segmentation in 
Motivations Analysis in Ecotourism Through an Empirical Application:

Segmentation, Characteristics and Motivations of the Consumer

ecotourism, the findings suggest that the market can be divided into three groups based on the motivations of tourists. The first of them formed by the segment "Multiple Motives", with high motivation in all motivational variables, so that the tourist has several reasons to visit the place. The second segment called "Nature" that have high motivations in aspects related to nature and experience new things.

The third group called "Reward and escape", who have high motivations related to nature, fun, and experience with new things and different cultures. The profiles of these three segments showed a statistically significant difference in relation to satisfaction and intentions to return to the destination. Therefore, the segment "Multiples Motive" have higher levels of satisfaction and intentions to return to the destination in relation to others, so it should enhance the offer to this segment of various activities related to nature, culture, fun, social aspects and personal aspects. Likewise, the "Nature" segment is the segment with the lowest levels of satisfaction and the intention to return to the destination in relation to the others. So it should improve the offer of nature enjoyment, such as observation and education about flora and fauna. In contrast, in the "Reward and escape" segment, they have high levels of intentions to return to the destination. Therefore, activities related to fun and experience with new things should be offered to this segment.

The "Multiple Motives" group and the "Nature" group mentioned in this study are similar to the Nature group and the Multiple Motive group found by Cordente-Rodríguez et al. (2014). However, this study provides information from a third group called "Reward and Escape", so it should adapt an offer to this segment related to fun and experience with new things. As a conclusion, the motivational dimensions in ecotourism are related to "Selfdevelopment", "Interpersonal relationships", "Building personal relationships and Egodefensive function", "Reward", "Escape", "Nature appreciation". "Self-development" is the most important motivational dimension. In ecotourism there are several groups based on the motivations of tourists, several things motivate one group at the same time, called "Multiple motives" another that is only motivated by nature, named "Nature" and the last one that is motivated for fun and experience with new things, named "Reward and Escape".

Among the practical implications, the findings of this study help tourism managers to establish marketing strategies and to improve the service according to the main motivational factors found, aiming to increase the impulse to visit these protected areas. Moreover, they can adapt the offer according to the characteristics of each segments found, in order to increase the satisfaction level of tourists and the interest to return to these protected areas. This study contributes to public institutions and private companies; they can improve the tourist offer in the destination and develop a more efficient planning. The main limitation of the investigation is the temporality, during the study. As a future line of research, it is recommended to carry out a study about offered products that adapt to the proposed segmentation, especially to the segment of tourists who seek fun and experience with new things.

\section{REFERENCES}

Álvarez, E. G. (2012). Holidays in nature: reflections on the origin, theory and practice of ecotourism. Polígonos. Revista de Geografía, (14), 17-52. http://dx.doi.org/10.18002/pol.voi14.488.

Barić, D., Anić, P., \& Macías Bedoya, A. (2016). Combining benefit-sought segmentation and service quality gap analysis: Case study of Paklenica National Park, Croatia. Turizam: međunarodni znanstveno-stručni časopis, 64(1), 7-25. https://hrcak.srce.hr/154829.

Broad, S., \& Jenkins, J. (2008). Gibbons in their midst? Conservation volunteers' motivations at the gibbon rehabilitation project, Phuket, Thailand. In K. Lyon \& S. Wearing (Eds.), Journeys of discovery in volunteer tourism (72-85). Cambridge, MA: CABIPublishing. 
Carvache-Franco, M., Segarra-Oña, M., \& Carrascosa-López, C. (2019). Segmentation by Motivation in Ecotourism: Application to Protected Areas in Guayas, Ecuador. Sustainability, 11(1), 240. https://doi.org/10.3390/su11010240.

Cheng, A., Gursoy, D. \& Del Chiappa, G. (2016). The influence of materialism on ecotourism attitudes and behaviors. Journal of Travel Research, 55(2), 176-189. https://doi.org/10.1177\%2Fo047287514541005.

Chikuta, O., du Plessis, L., \& Saayman, M. (2017). Nature-based travel motivations for people with disabilities. African Journal of Hospitality, Tourism and Leisure, 6(1), 1-16. http://www.ajhtl.com/.

Chow, A. S., Cheng, I. N., \& Cheung, L. T. (2019). Self-determined travel motivations and ecologically responsible attitudes of nature-based visitors to the Ramsar wetland in South China. Annals of Leisure Research, 22(1), 42-61. https://doi.org/10.1080/11745398.2017.1359791.

Cordente-Rodríguez, M., Mondéjar-jiménez, J., \& Villanueva-Álvaro, J. (2014): Sustainability of nature: the power of the type of visitors. Environmental Engineering and Management Journal, 13(10), 24372447. 13, No. 10, 2437-2447. http://omicron.ch.tuiasi.ro/EEMJ/.

Crompton, J.L. (1979). Motivations for pleasure vacation. Annals of tourism research, 6(4), $408-424$. https://doi.org/10.1016/0160-7383(79)90004-5.

Del Valle Melendo, J. (2007). Protected natural spaces and rural development: the case of Sobrarbe community. Revista de Desarrollo Rural y Cooperativismo Agrario, 2006(10), 175-194.

Díaz-Pérez, F.M., Bethencourt-Cejas, M., \& Álvarez-González, J.A. (2005). The segmentation of canary island tourism markets by expenditure: Implications for tourism policy. Tourism Management, 26, 961-964. https://doi.org/10.1016/j.tourman.2004.06.009.

Fodness, D. (1994). Measuring tourist motivation. Annals of tourism research, 21(3), 555-581. https://doi.org/ 10.1016/0160-7383(94)90120-1.

Formica, S., \& Uysal, M. (1998). Market segmentation of an international cultural-historical event in Italy. Journal of travel research, 36(4), 16-24. https://doi.org/10.1177\%2Fo04728759803600402.

Galley, G., \& Clifton, J. (2004). The motivational and demographic characteristics of research ecotourists: Operation Wallacea volunteers in Southeast Sulawesi, Indonesia. Journal of Ecotourism, 3(1), 69-82. https://doi.org/10.1080/14724040408668150.

Goeldner, C. R., \& Ritchie, J. R. (2003). Tourism: principles, practices, philosophies. Hoboken, NJ: John Wiley \& Sons.

$\mathrm{Gu}$ XP, Lewis BJ, Niu LJ, et al. (2018) Segmentation by domestic visitor motivation: Changbai Mountain Biosphere Reserve, China. Journal of Mountain Science 15(8). https://doi.org/ 10.1007/s11629-017-4708-1.

Ho, G.T., Ip, W.H., Lee, C.K.M., \& Mou, W.L. (2012). Customer grouping for better resources allocation using GA based clustering technique. Expert Systems with Applications, 39(2), 1979-1987. https://doi.org/ 10.1016/j.eswa.2011.08.045.

Houle, B.J., Sagarin, B.J., \& Kaplan, M.F. (2005). A functional approach to volunteerism: Do volunteer motives predict task preference? Basic and applied social psychology, 27(4), 337-344. https://doi.org/ 10.1207/s15324834basp2704_6.

Hultman, M., Kazeminia, A., \& Ghasemi, V. (2015). Intention to visit and willingness to pay premium for ecotourism: The impact of attitude, materialism, and motivation. Journal of Business Research, 68(9), 1854-1861. https://doi.org/10.1016/j.jbusres.2015.01.013.

Jalani, J.O. (2012). Local people's perception on the impacts and importance of ecotourism in Sabang, Palawan, Philippines. Procedia-Social and Behavioral Sciences, 57, 247-254. https://doi.org/10.1016/j.sbspro. 2012.09.1182.

Jang, S.S., \& Wu, C.M.E. (2006). Seniors' travel motivation and the influential factors: An examination of Taiwanese seniors. Tourism management, 27(2), 306-316. https://doi.org/10.1016/j.tourman.2004.11.006.

Jeong, Y., Zielinski, S., Chang, J. S., \& Kim, S. I. (2018). Comparing Motivation-Based and Motivation-Attitude-Based Segmentation of Tourists Visiting Sensitive Destinations. Sustainability, 10(10), 3615 https://doi.org/10.3390/su10103615.

Johns, N., \& Gyimothy, S. (2002). Market segmentation and the prediction of tourist behavior: The case of Bornholm, Denmark. Journal of Travel Research, 4O(3), 316-327. https://doi.org/10.1177\%2Fo047287502040003009.

Kastenholz, E., Davis, D., \& Paul, G. (1999). Segmenting tourism in rural areas: the case of North and Central Portugal. Journal of Travel research, 37(4), 353-363, https://doi.org/10.1177\%2F004728759903700 405.

Katz, D. (1960). The functional approach to the study of attitudes. Public opinion quarterly, 24(2), $163-204$. https://doi.org/10.1086/266945.

Kau, A.K., \& Lee, J. (1999). Determining tourist role typologies: an exploratory study of Singapore vacationers. Journal of Travel Research, 37(4), 382-390. https://doi.org/10.1177\%2F004728759903700408.

Kim, S. S., Kim, J. H., \& Ritchie, B. W. (2008). Segmenting overseas golf tourists by the concept of specialization. Journal of Travel \& Tourism Marketing, 25(2), 199-217. https://doi.org/10.1080/10548400802402958.

Kim, S.S., Crompton, J.L., \& Botha, C. (2000). Responding to competition: a strategy for sun/lost city, South Africa. Tourism Management, 21(1), 33-41. https://doi.org/10.1016/So261-5177(99)ooo94-1.

Kimmel, J.R. (1999). Ecotourism as environmental learning. The Journal of Environmental Education, 30(2), 40-44. https://doi.org/10.1080/o0958969909601869. 
Motivations Analysis in Ecotourism Through an Empirical Application: Segmentation, Characteristics and Motivations of the Consumer

Kotler, P., Bowen, J., \& Makens, J. (2003). Marketing for hospitality and tourism (3rded.). Upper Saddle River, NJ: Prentice Hall.

Lau, A. L., \& McKercher, B. (2004). Exploration versus acquisition: A comparison of first-time and repeat visitors. Journal of Travel Research, 42(3), 279-285. https://doi.org/10.1177\%2Fo047287503257502.

Lee, S., Lee, S., \& Lee, G. (2014). Ecotourists' motivation and revisit intention: A case study of restored ecological parks in South Korea. Asia Pacific Journal of Tourism Research, 19(11), 1327-1344 https://doi.org/10.1080/10941665.2013.852117.

Ma, A., Chow, A., Cheung, L., Lee, K., \& Liu, S. (2018). Impacts of Tourists' Sociodemographic Characteristics on the Travel Motivation and Satisfaction: The Case of Protected Areas in South China. Sustainability, 10(10), 3388. https://doi.org/10.3390/su10103388.

McGehee, N. G., \& Kim, K. (2004). Motivation for agri-tourism entrepreneurship. Journal of travel research, 43(2), 161-170. https://doi.org/10.1177\%2Foo47287504268245.

Meiriño, R. C., Brea, J. A. F., Vila, N. A., \& López, E. R. (2016). Market segmentation in an inland tourist destination. The case of A Ribeira Sacra (Ourense). Pasos, 14(2), 369.

Ministry of the Environment of Ecuador (2018). Retrieved from: http://areasprotegidas.ambiente.gob.ec/es/ noticias/mae-present\% $\mathrm{C}_{3} \% \mathrm{~B} 3$-el-portal-web-de-\% $\mathrm{C}_{3} \%$ A1reas-protegidas.

Neuts, B., Romão, J., Nijkamp, P., \& Shikida, A. (2016). Market segmentation and their potential economic impacts in an ecotourism destination: An applied modelling study on Hokkaido, Japan. Tourism Economics, 22(4), 793-808. https://doi.org/10.1177\%2F1354816616654252.

Nickerson, N. P., Jorgenson, J., \& Boley, B. B. (2016). Are sustainable tourists a higher spending market? Tourism Management, 54, 170-177. https://doi.org/10.1016/j.tourman.2015.11.009.

Panin, B. \& Mbrica, A. (2014). Potentials of ecotourism as a rural development tool on the base of motivation factors in Serbia. Sustainable agriculture and rural development in terms of the republic of Serbia strategic goals realization within the Danube region. Rural development and (un) limited resources, 597.

Park, D. B., \& Yoon, Y. S. (2009). Segmentation by motivation in rural tourism: A Korean case study. Tourism management, 3o(1), 99-108. https://doi.org/10.1016/j.tourman.2008.03.011.

Pearce, P. (2013). The social psychology of tourist behaviour: International series in experimental social psychology. United States of America: Elsevier.

Pesonen, J.A. (2012). Segmentation of rural tourists: Combining push and pull motivations. Tourism and Hospitality Management, 18(1), 69-82. https://hrcak.srce.hr/83824.

$\mathrm{Plog}$, S. C. (1974). Why destination areas rise and fall in popularity. Cornell hotel and restaurant administration quarterly, 14(4), 55-58.

Pulido-Fernández, J.I., \& Sánchez-Rivero, M. (2010). Attitudes of the cultural tourist: A latent segmentation approach. Journal of Cultural Economics, 34(2), 111-129. https://doi.org/10.1007/s10824-010-9115-1

Rivera Mateos, N. (2010). Active tourism in nature and leisure spaces in Andalusia: Territorial aspects, public policies and planning strategies. Andalucía Meeting: Ministry of Tourism, Trade and Sport. Doctoral Thesis.

Schewe, Ch. (1990). Get in position for the older market. American Demographics, 12(6), 38-44.

Smith, M. B., Bruner, J.S. \& White, R.W. (1956). Opinions and personality. New York, NY: Wiley.

Strydom, A.J., Mangope, D., \& Henama, U.S. (2019). Making Community-Based Tourism Sustainable: Evidence From The Free State Province, South Africa. GeoJournal of Tourism and Geosites, 24(1), 7-18. https://doi.org/10.30892/gtg.24101-338.

Swanson, K.K., \& Horridge, P.E. (2006). Travel motivations as souvenir purchase indicators. Tourism management, 27(4), 671-683. https://doi.org/10.1016/j.tourman.2005.03.001

Tao, T.C., \& Wall, G. (2009). Tourism as a sustainable livelihood strategy. Tourism Management, 30(1), 90-98. https://doi.org/10.1016/j.tourman.2008.03.009.

Vijulie, I., Matei, E, Preda, M., Manea, G., Cuculici, R., Mareci, A. (2018). Tourism - a viable alternative for the development of rural mountainous communities. Case study: Eftimie Murgu, Caraş-Severin County, Romania. GeoJournal of Tourism and Geosites. 22(2), 419-431. https://doi.org/10.30892/gtg.22212-299.

Weaver, D.B., \& Lawton, L.J. (2002). Overnight ecotourist market segmentation in the Gold Coast hinterland of Australia. Journal of Travel Research, 4O(3), 270-28o. https://doi.org/10.1177\%2Fo04728750204000305.

Wurzinger, S., \& Johansson, M. (2006). Environmental concern and knowledge of ecotourism among three groups of Swedish tourists. Journal of Travel Research, 45(2), 217-226. https://doi.org/10.1177\%2 Foo47287506291602.

Xia, J.C., Evans, F.H., Spilsbury, K., Ciesielski, V., Arrowsmith, C., \& Wright, G. (2010). Market segments based on the dominant movement patterns of tourists. Tourism management, 31(4), 464-469. https://doi.org/10.1016/j.tourman.2009.04.013.

Yolal, M., Rus, R.V., Cosma, S., \& Gursoy, D. (2015). A pilot study on spectators'motivations and their socioeconomic perceptions of a film festival. Journal of Convention \& Event Tourism, 16(3), 253-271. https://doi.org/10.1080/15470148.2015.1043610.

Submitted:

13.11.2018
Revised:

18.01.2019
Accepted and published online 22.01.2019 